\title{
Postnatal care for newborns in Bangladesh: The importance of health-related factors and location
}

\author{
Kavita Singh ${ }^{1,2}$, Paul Brodish ${ }^{1}$, \\ Mahbub Elahi Chowdhury ${ }^{3}$, \\ Taposh Kumar Biswas ${ }^{3}$, Eunsoo \\ Timothy Kim², Christine \\ Godwin², Allisyn Moran ${ }^{4}$ \\ ${ }^{1}$ MEASURE Evaluation/Carolina \\ Population Center, University of North \\ Carolina at Chapel Hill, Chapel Hill, \\ North Carolina, USA \\ ${ }^{2}$ Department of Maternal and Child \\ Health, Gillings School of Global Public \\ Health, University of North Carolina at \\ Chapel Hill, Chapel Hill, North Carolina, \\ USA \\ ${ }^{3}$ International Centre for Diarrhoeal \\ Disease Research, Bangladesh (icddr,b), \\ Dhaka, Bangladesh \\ ${ }^{4}$ Global Health Fellows Program II, \\ United States Agency for International \\ Development (USAID), Washington, \\ D.C., USA, and Abuja, Nigeria
}

Background Bangladesh achieved Millennium Development Goal 4, a two thirds reduction in under-five mortality from 1990 to 2015. However neonatal mortality remains high, and neonatal deaths now account for $62 \%$ of under-five deaths in Bangladesh. The objective of this paper is to understand which newborns in Bangladesh are receiving postnatal care (PNC), a set of interventions with the potential to reduce neonatal mortality.

Methods Using data from the Bangladesh Maternal Mortality Survey (BMMS) 2010 we conducted logistic regression analysis to understand what socio-economic and health-related factors were associated with early postnatal care (PNC) by day 2 and PNC by day 7. Key variables studied were maternal complications (during pregnancy, delivery or after delivery) and contact with the health care system (receipt of any antenatal care, place of delivery and type of delivery attendant). Using data from the BMMS 2010 and an Emergency Obstetric and Neonatal Care (EmONC) 2012 needs assessment, we also presented descriptive maps of PNC coverage overlaid with neonatal mortality rates.

Results There were several significant findings from the regression analysis. Newborns of mothers having a skilled delivery were significantly more likely to receive PNC (Day 7: OR=2.16, 95\% confidence interval (CI) 1.81, 2.58; Day 2: OR=2.11, 95\% CI 1.76). Newborns of mothers who reported a complication were also significantly more likely to receive PNC with odds ratios varying between 1.3 and 1.6 for complications at the different points along the continuum of care. Urban residence and greater wealth were also significantly associated with PNC. The maps provided visual images of wide variation in PNC coverage and indicated that districts with the highest PNC coverage, did not necessarily have the lowest neonatal mortality rates.

Conclusion Newborns of mothers who had a skilled delivery or who experienced a complication were more likely to receive PNC than newborns of mothers with a home delivery or who did not report a complication. Given that the majority of women in Bangladesh have a home delivery, strategies are needed to reach their newborns with PNC. Greater focus is also needed to reach poor women in rural areas. Engaging community health workers to conduct home PNC visits may be an interim strategy as Bangladesh strives to increase skilled delivery coverage.

The prevention of neonatal mortality has become a global priority because of the high mortality experienced by newborns and the difficulty in achieving improvements in their survival. Neonatal mortality now accounts for $45 \%$ of under-five mortality which translates to 2.8 million deaths within the first 28 days 
of life. On a global level neonatal mortality rates have declined from 33 to 19 deaths per 1000 live births (from 1990 to 2015), but this 47\% reduction is much less than the 58\% reduction seen in deaths among post-neonatal children under-five [1]. In addition, an estimated 2.6 million stillbirths occur each year, though only a fraction of these deaths are recorded in vital registration systems [2-4]. An estimated 46\% of stillbirths are intrapartum or "fresh" indicating that the fetus died after the onset of labor and perhaps could have been saved with appropriate interventions at delivery [3].

Every Newborn is an action plan focused on enabling countries to prevent neonatal deaths and stillbirths [4]. The plan emphasizes the critical periods of labor, birth and the first week of life as time points when interventions can achieve maximum impact on saving newborn lives. The plan is an extension of the United Nation's Every Woman Every Child movement and includes a vision, goals, strategies, and priorities for reducing newborn and stillbirth deaths. To achieve these goals, Every Newborn lays out key strategic objectives: 1 . Improving care at birth, 2. Improving the quality and equity of maternal and newborn care, 3. Reaching every woman and newborn and achieving impact at scale, 4. Harnessing the power of parents, families and communities, and 5. Counting every newborn through measurement, programtracking and accountability. Referral and follow-up care for low birth weight and sick newborns is also crucial given that prematurity and low birth weight are major predicators of neonatal mortality.

A continuum of services is needed to enhance newborn survival. Essential newborn care (ENC) involves care soon after birth and includes hygienic care, thermal control, support for breastfeeding and resuscitation with bag and mask, if needed [4]. Such interventions can address the main causes of neonatal mortality such as intrapartum related birth asphyxia and complications due to prematurity and low birth weight, which account for more than half of neonatal deaths [5]. Complementing essential newborn care is postnatal care (PNC) for the newborn, a package of interventions delivered after birth that includes the promotion of immediate and exclusive breastfeeding (for children less than 6 months of age), hand-washing, examination of mother and child for danger signs and appropriate referral for medical care [6]. Interventions provided as part of PNC can prevent some newborn complications such as sepsis, meningitis, pneumonia and diarrhea. PNC could be a means of providing follow-up care to newborns who were born premature and/or of low birth weight and provides an opportunity to check all newborns for illnesses that may have arisen since delivery [4].

Under-five mortality in Bangladesh has been steadily declining from 144 deaths per 1000 live births to 38 deaths per 1000 live births in the period between 1990 and 2015 [1]. Though Bangladesh laudably achieved the Millennium Development Goal (MDG) 4 target of a two-thirds reduction in under-five mortality, the burden of neonatal mortality continues to remain a concern. Neonatal mortality also declined from 63/1000 to 23/1000 during the same time period, but the magnitude of the decline was not as great as for under-five mortality. The proportion of neonatal deaths out of all under-five deaths actually increased from 44\% to 62\% from 1990 to 2015 [1]

Promotion of PNC has been emphasized in the National Neonatal Health Strategy and Guidelines (NNHS) of Bangladesh, and PNC is provided free of charge at government health facilities. PNC is provided both at health facilities and during home visits by community health workers in efforts to make the service accessible from the community to tertiary level. During home visits community health workers focus on the i) promotion of newborn care (early/exclusive breastfeeding, warmth, hygiene); ii) promotion of nutrition $\&$ family planning counseling to mothers; iii) providing information about danger signs of both mother and newborn; iv) Identification of danger signs in newborn and referral; v) support for breastfeeding; and vi) care of low birth weight infant (feeding, skin-to-skin contact) $[7,8]$.

Studies in Bangladesh have found that socioeconomic factors such as education $[9,10]$ and wealth have an influence on PNC coverage for newborns [11-16]. A study by Anwar et al. 2008 found that having at least one ANC visit [14] was associated with higher utilization of PNC, suggesting that prior contact with the health care system may be important. A qualitative study by Syed et al. 2008 found that mothers did not perceive PNC for themselves or their babies to be of much value unless they had a complication or their newborn was sick. The same study found that knowledge of maternal and newborn complications was often limited and initial care-seeking was often with a non-formal provider [17]. No quantitative studies in Bangladesh have looked at the role of complications on receipt of PNC for newborns.

The main aim of this study is to delve deeper into the question of which newborns in Bangladesh are receiving PNC by exploring not just socio-economic factors but also health-related factors, including maternal complications and contact with the health system. Our aim is to understand whether these factors, which have not been extensively studied in the literature, are associated with PNC. A secondary aim is to 
use maps to descriptively present geographic variability in PNC coverage and neonatal mortality. Maps can be a useful means to pinpoint geographic areas which need more programmatic focus.

\section{METHODS}

\section{Data and sample}

Data came from the 2010 Bangladesh Maternal Mortality Survey (BMMS), a large-scale survey of 175000 households [18]. The BMMS employed a multi-stage selection procedure designed to provide representative samples for maternal mortality at the national level and representative estimates at the national, urban/rural, divisional, and district levels for most other indicators. The BMMS Women's Long Questionnaire, which collected socio-economic and health-related information from approximately 62000 ever-married women aged 13-49, was used in this study. We also obtained information on household wealth from the BMMS Household Questionnaire. Because the primary outcome of interest was PNC for the most recent birth, we restricted the sample to those women who had a live birth in the past six years for a total sample size of 25014 mothers.

Data for the maps came from the BMMS 2010 as well as from a 2012 Needs Assessment of Emergency Obstetric and Newborn Care (EmONC) [19]. The BMMS 2010 provided the PNC data and populationlevel neonatal mortality estimates for all districts while the EmONC assessment provided data on facilitylevel neonatal mortality for 24 of the 64 districts of Bangladesh.

This study was reviewed by the Institutional Review Board (IRB) at the University of North Carolina at Chapel Hill and was exempted from needing ethics review approval because of the secondary nature of the analysis.

\section{Descriptive and regression analyses}

\section{Outcomes}

We calculated simple weighted descriptive statistics and chi-square analyses on all predictor and demographic variables, comparing women who reported receiving PNC on or before day 7 and on or before day 2 (early PNC) to those who did not. The sample for early PNC is a subset of the larger PNC on or before day 7 sample. Early PNC was defined as within a day for facility births and within two days for non-facility births. The WHO indicates that PNC should be given to newborns within 24 hours for both facility births and as soon as possible for non-facility births $[6,20]$. We therefore included day 2 as relevant for early PNC for non-facility births.

\section{Key independent variables}

Our key predictor variables were focused on access to maternal health services and the presence of complications. In terms of maternal health services we included receipt of ANC, type of delivery attendant (Skilled Birth Attendant (SBA) or non-SBA), place of delivery (facility vs non-facility). A SBA was defined according to the World Health Organization's definition as "an accredited health professional - such as a midwife, doctor or nurse - who has been educated and trained to proficiency in the skills needed to manage normal (uncomplicated) pregnancies, childbirth and the immediate postnatal period, and in the identification, management and referral of complications in women and newborns" [21]. We, thus, defined a SBA as an accredited doctor, nurse or midwife. All others including traditional birth attendants (TBAs) were defined as non-SBAs. We looked at both the type of delivery attendant and place of delivery because Bangladesh promotes a strategy of home deliveries by SBAs when facility delivery is not feasible [22,23]. Complications reported by the mother at labor, delivery and after delivery were also key measures in our analysis. Though the BMMS included questions on timing of complication, questions on specific types of complications were not included. We were not able to include four or more ANC visits and low birth weight in our analysis because of a large amount of missing data, and data on neonatal complications were not available.

\section{Regression analysis}

We performed weighted logistic regression models predicting receipt of the PNC outcomes, controlling for maternal age, parity, highest level of education, urban residence, marital status, and wealth quintile. 
The wealth index was constructed from data on ownership of household items including bathroom facilities, roofing, and flooring. Each asset was assigned a weight (factor score) generated through principle components analysis. Each household's scores were then summed; individuals were ranked according to the total score of the household in which they resided [18]). All analyses were performed using Stata v. 14.

\section{Maps and chi-square comparisons}

Descriptive maps of PNC by day 7 and early PNC were interposed with data on population-level neonatal mortality and facility-level neonatal mortality to present subnational level variation in PNC coverage and neonatal mortality. We also performed $\chi^{2}$ analyses of the key independent variables and PNC with neonatal mortality. Studying associations between PNC and neonatal mortality, however, has its limitations. The data do not allow for a determination of whether or not deaths on the first day of life occurred to newborns before they were even eligible for PNC [9]. For example, there could be some left censoring in that some newborns might have died within minutes of birth before they could have received a PNC check, but the data does not disaggregate deaths on the first day into hours or minutes.

\section{RESULTS}

Table 1 reports sample characteristics for PNC by day 7, while Table 2 does the same for early PNC. Given that early PNC is a subset of the PNC by day 7 outcome, the number of women who received early PNC is smaller than PNC by day 7 (7461 vs 8258). Thirty-three percent of respondents reported receipt of PNC by day 7, while 30\% reported early PNC. For every characteristic except marital status, there were differences between women receiving PNC by day 7 and not receiving PNC by day 7 . For example, women who reported contact with the health system in terms of ANC, facility delivery or delivery with a SBA were more likely to report PNC by day 7 . Women who reported a complication during pregnancy, delivery or after delivery as well as urban, wealthier and more educated were also more likely to indicate their newborns received PNC by day 7. Results were similar when comparing women receiving early PNC to those who did not (Table 2).

Table 3 shows results from the logistic regressions of PNC by day 7 and by day 2. Confirming some of the findings shown in Tables 1 and $\mathbf{2}$, controlling for maternal demographic characteristics, having had a skilled delivery significantly increased the odds of reporting PNC by day 7 and by day 2 by over 2.1 times (odds ratio $(\mathrm{OR})=2.16,95 \%$ confidence interval $(\mathrm{CI}) 1.81,2.58$; OR=2.11, 95\% CI 1.76, 2.54, respectively). Having had a home delivery significantly decreased the likelihood of PNC by about $85 \%$ $(\mathrm{OR}=0.15,95 \%$ CI $0.12,0.18 ; \mathrm{OR}=0.14,95 \% \mathrm{CI} 0.12,0.17$, respectively). Reporting complications during pregnancy, delivery and after delivery significantly increased the odds of reporting PNC by between 1.3 and 1.6 times. Urban residence significantly increased the odds of reporting PNC by day 7 or by day 2 by about 1.4 times ( $\mathrm{OR}=1.38,95 \% \mathrm{CI} 1.22,1.55$; OR $=1.40,95 \% \mathrm{CI} 1.23,1.59$, respectively). Being in the top three wealth quintiles also increased the odds of reporting PNC by day 7 and by day 2 by between 1.5 and 2.3 times.

Figures 1 and 2 present descriptive maps of PNC coverage interposed with population-level neonatal mortality (Figure 1) and facility-level neonatal mortality (Figure 2). Overall, there is wide variation in the PNC (from 4\% to 64\%) and population-level neonatal mortality rates (from 1.6 per 1000 to 96.2 per 1000) within Bangladesh. Districts with the lowest neonatal mortality do not always have the highest PNC coverage and vice versa. Chi-square statistics for key independent variables and PNC with neonatal mortality indicate significantly higher mortality for newborns receiving PNC by day 2 and for newborns of mothers having a complication and a skilled delivery. These results are presented in Figure 3.

\section{DISCUSSION}

PNC is a package of interventions intended for all newborns and has both a preventative focus and curative focus. In our study of PNC in Bangladesh we find that newborns whose mothers had a facility delivery or who had a complication were likely to have a PNC check than newborns of mothers who delivered at home or did not have a complication. Given that $79 \%$ of women in our sample had a home birth, efforts are needed to ensure all newborns are reached.

PNC for newborns may not always be perceived to be necessary by mothers and their families in Bangladesh [17]), unless there is a complication or the newborn appears sick. Education of families on the im- 
Table 1. Sample characteristics by postnatal care on or before day $7(n=25014)$

\begin{tabular}{|c|c|c|c|c|c|}
\hline & No PNC by DA & & PNC by day 7 & & \\
\hline Characteristic & $\mathbf{n}$ & $(\%)$ & $\mathbf{n}$ & $(\%)$ & $\mathbf{P}$ \\
\hline Total & 16756 & 67.0 & 8258 & 33.0 & \\
\hline \multicolumn{6}{|l|}{ Predictor variables } \\
\hline \multicolumn{6}{|l|}{ Delivery: } \\
\hline - Unskilled & 15307 & 93.3 & 3489 & 46.0 & \\
\hline - Skilled & 1449 & 6.7 & 4769 & 54.0 & $<0.001$ \\
\hline \multicolumn{6}{|l|}{ Home delivery: } \\
\hline- No & 1078 & 5.2 & 4622 & 52.7 & \\
\hline- Yes & 15678 & 94.8 & 3636 & 47.3 & $<0.001$ \\
\hline \multicolumn{6}{|l|}{ Any antenatal care (ANC): } \\
\hline$-\mathrm{No}$ & 6615 & 40.5 & 1135 & 14.8 & \\
\hline- Yes & 10141 & 59.5 & 7123 & 85.2 & $<0.001$ \\
\hline \multicolumn{6}{|c|}{ Reported complications during pregnancy: } \\
\hline$-\mathrm{No}$ & 11190 & 66.5 & 4158 & 49.7 & \\
\hline- Yes & 5566 & 33.5 & 4100 & 50.3 & $<0.001$ \\
\hline \multicolumn{6}{|c|}{ Reported complications during delivery: } \\
\hline$-\mathrm{No}$ & 13099 & 78.0 & 5209 & 62.5 & \\
\hline- Yes & 3657 & 22.0 & 3049 & 37.5 & $<0.001$ \\
\hline \multicolumn{6}{|c|}{ Reported complications after delivery: } \\
\hline$-\mathrm{No}$ & 13818 & 82.8 & 6270 & 75.9 & \\
\hline - Yes & 2938 & 17.2 & 1988 & 24.1 & $<0.001$ \\
\hline \multicolumn{6}{|c|}{ Demographic characteristics } \\
\hline \multicolumn{6}{|c|}{ Maternal age (years): } \\
\hline-13 to 19 & 1950 & 11.7 & 914 & 11.5 & \\
\hline-20 to 24 & 5363 & 32.6 & 2938 & 36.2 & \\
\hline-25 to 29 & 4782 & 28.3 & 2329 & 27.9 & \\
\hline-30 to 34 & 2677 & 15.9 & 1268 & 14.8 & \\
\hline-35 to 39 & 1324 & 7.6 & 574 & 6.7 & \\
\hline-40 to 44 & 485 & 2.9 & 179 & 2.1 & \\
\hline-45 to 49 & 175 & 1.0 & 56 & 0.7 & $<0.001$ \\
\hline \multicolumn{6}{|c|}{ Highest level of education (class): } \\
\hline - None & 4964 & 30.2 & 1269 & 16.0 & \\
\hline-1 to 5 & 5658 & 33.3 & 2031 & 25.5 & \\
\hline-6 to 8 & 3402 & 20.7 & 1789 & 22.6 & \\
\hline$-9+$ & 2732 & 15.8 & 3169 & 35.9 & $<0.001$ \\
\hline \multicolumn{6}{|l|}{ Urban residence: } \\
\hline- No & 10773 & 81.9 & 3955 & 64.4 & \\
\hline - Yes & 5983 & 18.1 & 4303 & 35.6 & $<0.001$ \\
\hline \multicolumn{6}{|l|}{ Religion: } \\
\hline - Islam & 15349 & 92.4 & 7334 & 89.8 & \\
\hline - Hindu/other & 1407 & 7.6 & 924 & 10.2 & $<0.001$ \\
\hline \multicolumn{6}{|l|}{ Marital status: } \\
\hline - Currently not married & 324 & 1.8 & 127 & 1.5 & \\
\hline - Currently married & 16432 & 98.2 & 8131 & 98.5 & 0.199 \\
\hline \multicolumn{6}{|l|}{ Wealth index quintile: } \\
\hline - Poorest & 4234 & 26.4 & 790 & 10.8 & \\
\hline - Poorer & 3702 & 22.8 & 964 & 12.5 & \\
\hline - Middle & 3522 & 21.5 & 1384 & 18.0 & \\
\hline - Richer & 3047 & 17.7 & 1878 & 22.7 & \\
\hline - Richest & 2251 & 11.6 & 3242 & 35.9 & $<0.001$ \\
\hline
\end{tabular}

portance of PNC as a preventative service can lead to improvements in newborn health. Early treatment for illnesses such as pneumonia is crucial, and PNC offers an opportunity for health workers to look for signs of illnesses which may be missed by family members.

Traditional practices may prevent many mothers from leaving their homes for up to 40 days after delivery $[24,25]$. During this period of isolation, mothers are considered to be in a state of impurity and vulnerability to evil spirits [25]. Mothers often sleep on thin mats on the floor with their newborns to minimize the spread of pollution to others and protect themselves from spiritual attacks $[16,25]$. Husbands 
Table 2. Sample characteristics by postnatal care on or before day 2 (early PNC, $\mathrm{n}=25014$ )

\begin{tabular}{|c|c|c|c|c|c|}
\hline \multirow[b]{2}{*}{ Characteristic } & \multicolumn{2}{|c|}{ No PNC by day 2} & \multicolumn{2}{|c|}{ PNC by day 2} & \multirow[b]{2}{*}{$\mathbf{P}$} \\
\hline & $\mathrm{n}$ & $\%$ & $\mathbf{n}$ & $\%$ & \\
\hline Total & 17553 & 70.2 & 7461 & 29.8 & \\
\hline \multicolumn{6}{|l|}{ Predictor variables } \\
\hline \multicolumn{6}{|l|}{ Delivery: } \\
\hline - Unskilled & 15898 & 92.6 & 2898 & 42.6 & \\
\hline - Skilled & 1655 & 7.4 & 4563 & 57.4 & $<0.001$ \\
\hline \multicolumn{6}{|l|}{ Home delivery: } \\
\hline$-\mathrm{No}$ & 1247 & 5.7 & 4453 & 56.4 & \\
\hline - Yes & 16306 & 94.3 & 3008 & 43.6 & $<0.001$ \\
\hline \multicolumn{6}{|l|}{ Any antenatal care (ANC): } \\
\hline$-\mathrm{No}$ & 6786 & 39.7 & 964 & 14.0 & \\
\hline- Yes & 10767 & 60.3 & 6497 & 86.0 & \\
\hline \multicolumn{6}{|c|}{ Reported complications during pregnancy: } \\
\hline- No & 11584 & 65.7 & 3764 & 49.8 & \\
\hline -Yes & 5969 & 34.3 & 3697 & 50.2 & $<0.001$ \\
\hline \multicolumn{6}{|c|}{ Reported complications during delivery: } \\
\hline- No & 13637 & 77.5 & 4671 & 61.9 & \\
\hline- Yes & 3916 & 22.5 & 2790 & 38.1 & $<0.001$ \\
\hline \multicolumn{6}{|c|}{ Reported complications after delivery: } \\
\hline$-\mathrm{No}$ & 14402 & 82.4 & 5686 & 76.2 & \\
\hline- Yes & 3151 & 17.6 & 1775 & 23.8 & $<0.001$ \\
\hline \multicolumn{6}{|c|}{ Demographic characteristics } \\
\hline \multicolumn{6}{|c|}{ Maternal age (years): } \\
\hline-13 to 19 & 2036 & 11.7 & 828 & 11.5 & \\
\hline-20 to 24 & 5646 & 32.7 & 2655 & 36.4 & \\
\hline-25 to 29 & 4999 & 28.3 & 2112 & 28.0 & \\
\hline-30 to 34 & 2816 & 16.0 & 1129 & 14.5 & \\
\hline-35 to 39 & 1371 & 7.5 & 527 & 6.9 & \\
\hline-40 to 44 & 502 & 2.8 & 162 & 2.1 & \\
\hline-45 to 49 & 183 & 1.0 & 48 & 0.7 & $<0.001$ \\
\hline \multicolumn{6}{|c|}{ Highest level of education (class): } \\
\hline - None & 5122 & 29.8 & 1111 & 15.5 & \\
\hline-1 to 5 & 5924 & 33.3 & 1765 & 24.7 & \\
\hline-6 to 8 & 3567 & 20.8 & 1624 & 22.6 & \\
\hline$-9+$ & 2940 & 16.1 & 2961 & 37.2 & $<0.001$ \\
\hline \multicolumn{6}{|l|}{ Urban residence: } \\
\hline- No & 11226 & 81.6 & 3502 & 63.3 & \\
\hline- Yes & 6327 & 18.4 & 3959 & 36.7 & $<0.001$ \\
\hline \multicolumn{6}{|l|}{ Religion: } \\
\hline - Islam & 16072 & 92.3 & 6611 & 89.6 & \\
\hline - Hindu/other & 1481 & 7.7 & 850 & 10.4 & $<0.001$ \\
\hline \multicolumn{6}{|l|}{ Marital status: } \\
\hline - Currently not married & 340 & 1.8 & 111 & 1.5 & \\
\hline - Currently married & 17213 & 98.2 & 7350 & 98.5 & 0.2028 \\
\hline \multicolumn{6}{|l|}{ Wealth index quintile: } \\
\hline - Poorest & 4357 & 26.0 & 667 & 10.1 & \\
\hline - Poorer & 3835 & 22.6 & 831 & 11.9 & \\
\hline - Middle & 3697 & 21.6 & 1209 & 17.5 & \\
\hline - Richer & 3213 & 17.9 & 1712 & 22.9 & \\
\hline - Richest & 2451 & 12.0 & 3042 & 37.5 & $<0.001$ \\
\hline
\end{tabular}


Figure 1.

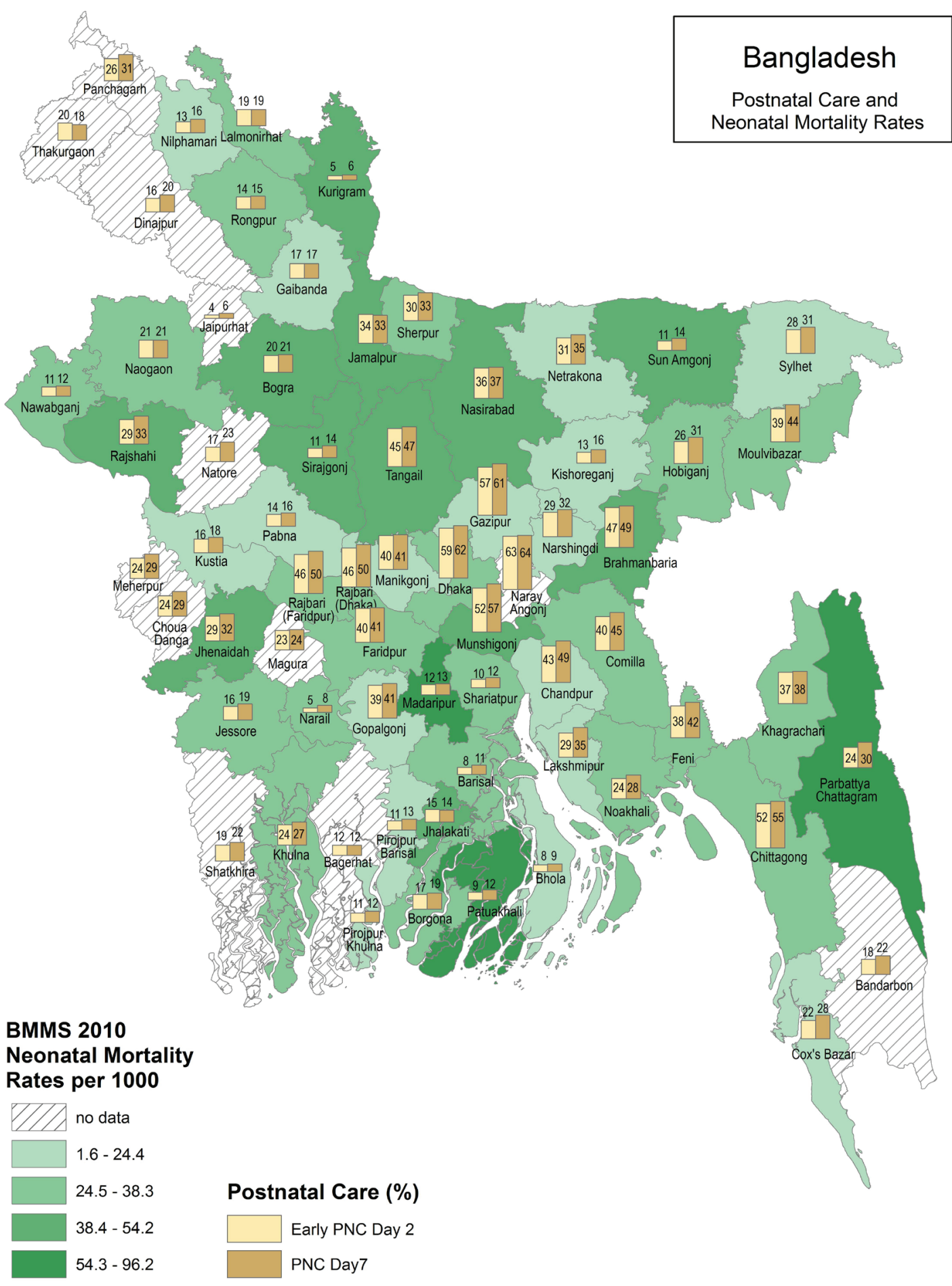

Figure 1. Postnatal care (PNC) and population-level neonatal mortality by district.

and mothers-in-law may also serve as gatekeepers to ensure minimal contact with outsiders during this period [25-28]. In light of these cultural issues, training community health workers to provide PNC for mothers and newborns at home, has surfaced as an interim solution to increasing the coverage of PNC $[24,29,30]$. Community health workers have the ability to gain the trust and support of mothers, fathers and mothers-in-law. They can engage these individuals on discussions concerning newborn care and any harmful traditional practices. For example, if newborns are sleeping on thin mats, community health workers can educate families on the risks of hypothermia. Studies conducted in rural Bangladesh have 
Figure 2.

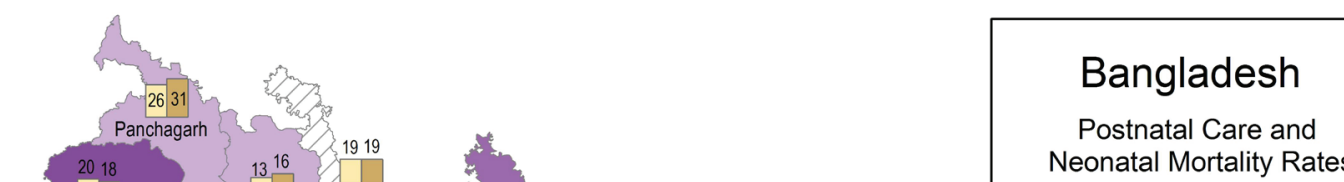

\section{EmONC 2012}

Neonatal Mortality

Rates per 1000
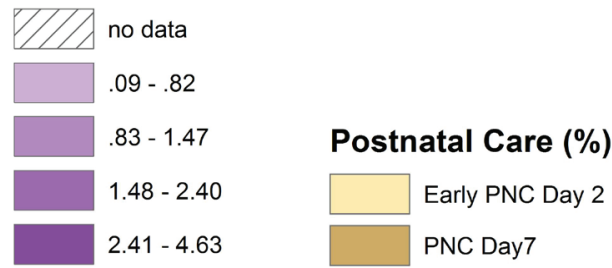

Neonatal Mortality Rates

Figure 2. Postnatal care (PNC) and facility-level neonatal mortality by district.

documented that community health workers are capable of correctly identifying sick newborns with a 6-sign or 7-sign clinical algorithm during their routine surveillance of newborns at home [28,31]. Home visits from community health workers by day 2 have been shown to reduce neonatal mortality [32]. Home visits have also been shown to be an effective means to assist mothers in overcoming breastfeeding problems [33].

In addition to identifying methods to reach more individual newborns, it is also important to study PNC coverage at a subnational level to enable countries to address geographic inequities. In Bangladesh there 
Table 3. Logistic regressions of postnatal care by day 7 and by day 2 on predictor variables $(n=25014)$

\begin{tabular}{|c|c|c|c|c|c|c|}
\hline \multirow[b]{2}{*}{ Characteristic } & \multicolumn{3}{|c|}{ PNC by day 7} & \multicolumn{3}{|c|}{ PNC By day 2} \\
\hline & Odds ratio & $95 \%$ CI & $\mathbf{P}$ & Odds ratio & $95 \%$ CI & $\mathbf{P}$ \\
\hline \multicolumn{7}{|l|}{ Predictor variables } \\
\hline Skilled delivery & 2.16 & $1.81-2.58$ & $<0.001$ & 2.11 & $1.76-2.54$ & $<0.001$ \\
\hline Home delivery & 0.15 & $0.12-0.18$ & $<0.001$ & 0.14 & $0.12-0.17$ & $<0.001$ \\
\hline Any antenatal care (ANC) & 1.74 & $1.58-1.92$ & $<0.001$ & 1.71 & $1.54-1.89$ & $<0.001$ \\
\hline Complications during pregnancy & 1.60 & $1.45-1.73$ & $<0.001$ & 1.49 & $1.36-1.64$ & $<0.001$ \\
\hline Complications at delivery & 1.48 & $1.34-1.63$ & $<0.001$ & 1.53 & $1.38-1.69$ & $<0.001$ \\
\hline Complications after delivery & 1.36 & $1.22-1.51$ & $<0.001$ & 1.32 & $1.18-1.48$ & $<0.001$ \\
\hline \multicolumn{7}{|l|}{ Demographic characteristics } \\
\hline \multicolumn{7}{|l|}{ Maternal age (years): } \\
\hline-13 to 19 & 1.00 & & & & & \\
\hline-20 to 24 & 1.12 & $0.98-1.27$ & 0.110 & 1.10 & $0.96-1.27$ & 0.172 \\
\hline-25 to 29 & 1.07 & $0.91-1.25$ & 0.431 & 1.06 & $0.90-1.26$ & 0.478 \\
\hline-30 to 34 & 1.02 & $0.84-1.23$ & 0.856 & 0.98 & $0.81-1.19$ & 0.841 \\
\hline - to 39 & 1.11 & $0.89-1.39$ & 0.362 & 1.18 & $0.93-1.50$ & 0.184 \\
\hline-40 to 44 & 1.13 & $0.84-1.52$ & 0.403 & 1.19 & $0.87-1.61$ & 0.272 \\
\hline- to 49 & 1.52 & $1.01-2.29$ & 0.047 & 1.52 & $0.98-2.37$ & 0.060 \\
\hline \multicolumn{7}{|l|}{ Parity: } \\
\hline-1 & 1.00 & & & & & \\
\hline$-2-3$ & 0.91 & $0.82-1.01$ & 0.069 & 0.92 & $0.82-1.02$ & 0.111 \\
\hline$-4+$ & 0.94 & $0.80-1.11$ & 0.450 & 0.91 & $0.76-1.08$ & 0.278 \\
\hline \multicolumn{7}{|l|}{ Highest level of education (class): } \\
\hline - None & 1.00 & & & & & \\
\hline-1 to 5 & 1.10 & $0.98-1.23$ & 0.091 & 1.06 & $0.94-1.20$ & 0.372 \\
\hline-6 to 8 & 1.08 & $0.94-1.23$ & 0.277 & 1.05 & $0.91-1.22$ & 0.492 \\
\hline$-9+$ & 1.14 & $0.99-1.31$ & 0.073 & 1.11 & $0.95-1.29$ & 0.174 \\
\hline \multicolumn{7}{|l|}{ Urban residence: } \\
\hline$-\mathrm{No}$ & 1.00 & & & & & \\
\hline - Yes & 1.38 & $1.22-1.55$ & $<0.001$ & 1.40 & $1.23-1.59$ & $<0.001$ \\
\hline \multicolumn{7}{|l|}{ Religion: } \\
\hline - Islam & 1.00 & & & & & \\
\hline - Hindu/other & 1.09 & $0.93-1.28$ & 0.284 & 1.07 & $0.91-1.27$ & 0.412 \\
\hline \multicolumn{7}{|l|}{ Marital status: } \\
\hline - Currently not married & 1.00 & & & & & \\
\hline - Currently married & 1.04 & $0.77-1.41$ & 0.791 & 1.04 & $0.76-1.44$ & 0.793 \\
\hline \multicolumn{7}{|l|}{ Wealth index quintile: } \\
\hline - Poorest & 1.00 & & & & & \\
\hline - Poorer & 1.15 & $1.00-1.32$ & 0.058 & 1.14 & $0.98-1.32$ & 0.090 \\
\hline - Middle & 1.47 & $1.29-1.68$ & $<0.001$ & 1.46 & $1.27-1.69$ & $<0.001$ \\
\hline - Richer & 1.65 & $1.42-1.91$ & $<0.001$ & 1.68 & $1.43-1.97$ & $<0.001$ \\
\hline - Richest & 2.32 & $1.97-2.74$ & $<0.001$ & 2.35 & $1.97-2.80$ & $<0.001$ \\
\hline Constant & 0.45 & $0.31-0.66$ & $<0.001$ & 0.40 & $0.27-0.60$ & $<0.001$ \\
\hline
\end{tabular}

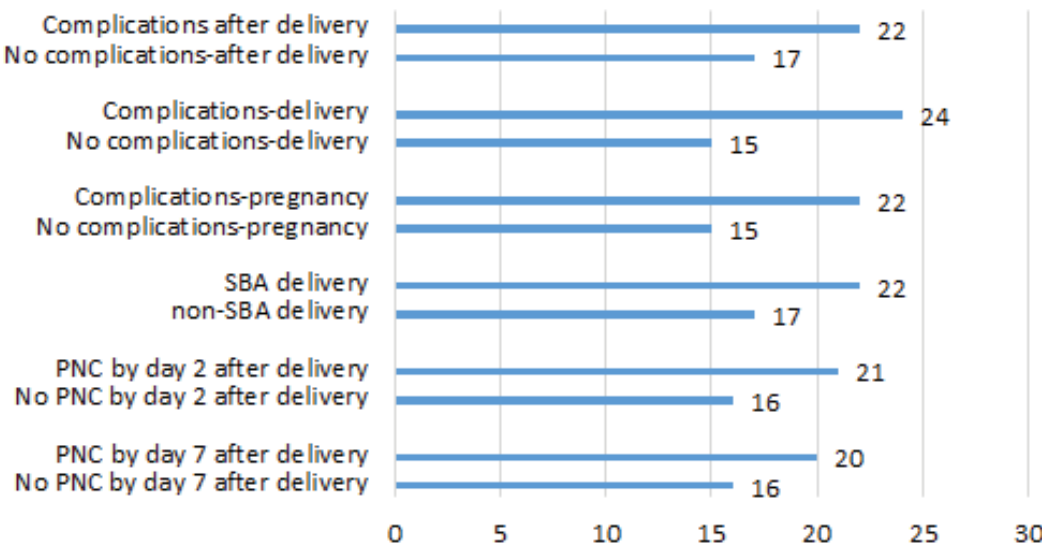

Figure 3. Bivariate associations between selection variables and neonatal mortality (per 1000). Note: All comparisons are significant at $\mathrm{P}<0.05$ or $\mathrm{P}<0.0001$ except for $\mathrm{PNC}$ by Day $7(\mathrm{P}=0.0635)$. PNC - postnatal care, SBA - skilled birth attendant. 
is wide variation in PNC coverage. Understanding why some districts have lower coverage than others can help inform intervention strategies. Traditional practices such as seclusion of the mother and newborn may be more prevalent in some districts than others, and thus engagement with communities on the importance of PNC (whether in a facility or in the home) may be particularly helpful.

Our maps also revealed that districts with the highest PNC coverage did not necessarily have the lowest neonatal mortality and vice versa. We further explain this finding through bivariate comparisons of our key independent variables and PNC with neonatal mortality. The findings indicated significantly higher neonatal mortality when there is a PNC by day 2 check, maternal complication and delivery with a skilled birth attendant. Families in Bangladesh seem to view PNC as a service needed only when there is a problem with the mother or newborn. According to the BMMS 2010, 56\% of mothers whose newborns did not receive PNC, indicated the reason was that the service was "not needed" [18]. Unfortunately, we lacked data on newborn complications, prematurity and low birth weight.

There are several limitations to this study including our inability to include certain measures including neonatal complications, four or more ANC visits and birthweight. Though we looked at bivariate associations of PNC with neonatal mortality, there could be some left censoring of the data in that some newborns could have died before they were eligible for PNC [9]. Another limitation is the measurement of PNC itself as some women may not realize their newborn is receiving a check. Direct questions on PNC without probes, as was used in the BMMS, may lead to an underestimation of coverage [34]. The BMMS did not include questions on content or quality of the PNC check, and future research is needed to develop measures on both content and quality of PNC.

Based on the findings of this study, several programmatic recommendations can be made. Both formal health workers and community health workers should provide PNC, a service essential for both for its preventative and curative elements. Particular efforts are needed to reach rural and poor women. Bangladesh has already taken relevant steps to reduce neonatal mortality by developing a National Newborn Health Strategy, which includes PNC provided by community health workers as a national health sector program approach [35]. Important considerations for such an approach are ensuring community health workers have the proper training, supplies and supervision to conduct their work. Community health workers also need to be notified of both facility and home births so that more newborns can be reached [36]. In addition to supporting community health workers, efforts are needed to increase the quality of PNC services in health facilities and to educate families on recognizing the value of PNC for seemingly healthy newborns as well as for sick newborns.

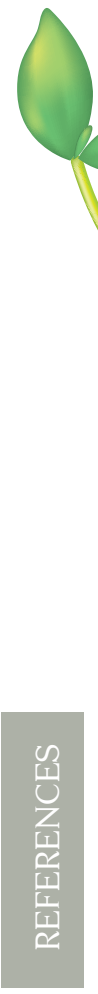

Acknowledgments: The authors would like to thank Becky Wilkes for assistance with the maps.

Disclaimers: The views expressed are those of the authors and do not necessarily reflect the views of USAID or the United States Government.

Funding: This study was carried out with support provided by the United States Agency for International Development (USAID) through MEASURE Evaluation (cooperative agreement AID-OAA-L-14-00004). We are grateful to the Carolina Population Center and its NIH Center grant (P2C HD050924) for general support.

Author Contributions: KS led conceptualization and writing of the paper. PB led data management and analysis. MEC and TKB provided information on context and gave substantial inputs on all versions of the paper. ETK and CG assisted with the literature review, and AM provided guidance on the structure of the paper and provided suggestions on all versions of the paper.

Conflict of interest declaration: The authors completed the Unified Competing Interest form at www.icmje. org/coi_disclosure.pdf (available upon request from the corresponding author), and report no conflicts of interest.

1 UNICEF. Levels \& trends in child mortality. Report 2015. Estimates developed by the UN Inter-agency Group for Child Mortality Estimation. New York: UNICEF; 2015.

2 Mullan Z, Horton R. Bringing stillbirths out of the shadows. Lancet. 2011;377:1291-2. Medline:21496920 doi:10.1016/ S0140-6736(11)60098-6

3 Lawn JE, Blencowe H, Pattinson R, Cousens S, Kumar R, Ibiebele I, et al. Stillbirths: Where? When? Why? How to make the data count? Lancet. 2011;377:1448-63. Medline:21496911 doi:10.1016/S0140-6736(10)62187-3

4 World Health Organization. Every newborn: an action plan to end preventable deaths. Geneva: WHO; 2014. 
5 Liu L, Johnson HL, Cousens S, Perin J, Scott S, Lawn J, et al. Global, regional, and national causes of child mortality: an updated systematic analysis for 2010 with time trends since 2000. Lancet. 2012;379:2151-61. Medline:22579125 doi:10.1016/S0140-6736(12)60560-1

6 World Health Organization and UNICEF Joint Statement: Home Visits for the Newborn Child: A Strategy to Improve Survival. Geneva: World Health Organization, USAID and Save the Children; 2009.

7 Health Newborn Network. Summary of Bangladesh Country experience - implementing PNC home visits: March 26, 2012. Available: http://www.healthynewbornnetwork.org/hnn-content/uploads/Country-Report-PNC-Home-Visits-Bangladesh.pdf. Accessed: 15 July 2017.

8 USAID. MCHIP and Save the Children. Postnatal Care Home Visits: A Review of the Current Status of Implementation in Five Countries. 2012. Available: http://www.mchip.net/sites/default/files/Postnatal\%20Care\%20Home\%20Visits.pdf. Accessed: 15 July 2017.

9 Singh K, Brodish P, Haney E. Postnatal care by provider type and neonatal death in sub-Saharan Africa: a multilevel analysis. BMC Public Health. 2014;14:941. Medline:25208951 doi:10.1186/1471-2458-14-941

10 Islam MA, Chowdhury RI, Akhter HH. Complications during pregnancy, delivery, and postnatal stages and place of delivery in rural Bangladesh. Health Care Women Int. 2006;27:807-21. Medline:17060180 doi:10.1080/07399330600880368

11 Amin R, Shah NM, Becker S. Socioeconomic factors differentiating maternal and child health-seeking behavior in rural Bangladesh: a cross-sectional analysis. Int J Equity Health. 2010;9:9-12. Medline:20361875 doi:10.1186/1475-9276-9-9

12 Chakraborty N, Islam MA, Chowdhury RI, Bari W. Utilisation of postnatal care in Bangladesh: evidence from a longitudinal study. Health Soc Care Community. 2002;10:492-502. Medline:12485137 doi:10.1046/j.1365-2524.2002.00389.x

13 Rahman MM, Haque SE, Sarwar Zahan M. Factors affecting the utilisation of postpartum care among young mothers in Bangladesh. Health Soc Care Community. 2011;19:138-47. Medline:20880103

14 Anwar I, Sami M, Akhtar N, Chowdhury M, Salma U, Rahman M, et al. Inequity in maternal health-care services: evidence from home-based skilled-birth-attendant programmes in Bangladesh. Bull World Health Organ. 2008;86:252-9. Medline:18438513 doi:10.2471/BLT.07.042754

15 Mahabub-Ul-Anwar M, Rob U, Talukder MN. Inequalities in maternal health care utilization in rural Bangladesh. Int Q Community Health Educ. 2006-2007;27:281-97. Medline:18573752 doi:10.2190/IQ.27.4.b

16 Darmstadt GL, Syed U, Patel Z, Kabir N. Review of domiciliary newborn-care practices in Bangladesh. J Health Popul Nutr. 2006;24:380-93. Medline:17591335

17 Syed U, Khadka N, Khan A, Wall S. Care-seeking practices in South Asia: using formative research to design program interventions to save newborn lives. J Perinatol. 2008;28:S9-13. Medline:19057572 doi:10.1038/jp.2008.165

18 NIPORT, icddr,b. National Institute of Population Research and Training (NIPORT), MEASURE Evaluation, and icddr,b Bangladesh Maternal Mortality and Health Care Survey 2010. Dhaka, Bangladesh: NIPORT, MEASURE Evaluation, and icddr,b; 2012.

19 Chowdhury ME, Roy L, Biswas TK, Rahman M, Akhter S, Sabir AA. A needs assessment study for emergency obstetric and newborn care (EmONC) services in 24 districts of Bangladesh. Dhaka: International Centre for Diarrhoeal Disease Research, Bangladesh (icddr,b); 2014.

20 World Health Organization (WHO). Maternal, newborn, child and adolescent health -Topics at a glance - Newborn health: Postnatal care. Geneva: World Health Organization; 2013.

21 World Health Organization. Making pregnancy safer: the critical role of the skilled attendant. A joint statement by WHO, ICM and FIGO. Geneva: WHO; 2004.

22 Blum LS, Sharmin T, Ronsmans C. Attending home vs. clinic-based deliveries: Perspectives of skilled birth attendants in Matlab, Bangladesh. Reprod Health Matters. 2006;14:51-60. Medline:16713879 doi:10.1016/S0968-8080(06)27234-3

23 Huque ZA, Leppard M, Mavalankar D, Akhter HH, Chowdhury TA. Safe motherhood programmes in Bangladesh. In: Berer M, Ravindra TKS, eds. Safe motherhood initiatives: Critical issues. London: Reprod Health Matters, 1999; p.5361.

24 Syed U, Asiruddin S, Helal MS, Mannan II, Murray J. Immediate and early postnatal care for mothers and newborns in rural Bangladesh. J Health Popul Nutr. 24:508-18. Medline:17591348

25 Winch PJ, Alam MA, Akther A, Afroz D, Ali NA, Ellis AA, et al. Local understandings of vulnerability and protection during the neonatal period in Sylhet district, Bangladesh: a qualitative study. Lancet. 2005;366:478-85. Medline:16084256 doi:10.1016/S0140-6736(05)66836-5

26 Moran AC, Winch PJ, Sultana N, Kalim N, Afzal KM, Koblinsky M, et al. Patterns of maternal care seeking behaviours in rural Bangladesh. Trop Med Int Health. 2007;12:823-32. Medline:17596248 doi:10.1111/j.1365-3156.2007.01852.x

27 Walton LM, Brown D. Cultural Barriers to Maternal Health Care in Rural Bangladesh. Online J Health Ethics. 2012. Available: https://papers.ssrn.com/sol3/papers.cfm?abstract_id=2042694.

28 Darmstadt GL, El Arifeen S, Choi Y, Bari S, Rahman SM, Mannan I, et al. Household surveillance of severe neonatal illness by community health workers in Mirzapur, Bangladesh: coverage and compliance with referral. Health Policy Plan. 2010;25:112-24. Medline:19917652 doi:10.1093/heapol/czp048

29 Choudhury N, Moran AC, Alam MA, Ahsan KZ, Rashid SF, Streatfield PK. Beliefs and practices during pregnancy and childbirth in urban slums of Dhaka, Bangladesh. BMC Public Health. 2012;12:791. Medline:22978705 doi:10.1186/14712458-12-791

30 Dynes M, Rahman A, Beck D, Moran A, Rahman A, Pervin J, et al. Home-based life saving skills in Matlab, Bangladesh: a process evaluation of a community-based maternal child health programme. Midwifery. 2011;27:15-22. Medline:19783081 doi:10.1016/j.midw.2009.07.009 
31 Darmstadt GL, Baqui AH, Choi Y, Bari S, Rahman SM, Mannan I, et al. Validation of a clinical algorithm to identify neonates with severe illness during routine household visits in rural Bangladesh. Arch Dis Child. 2011;96:1140-6. Medline:21965811 doi:10.1136/archdischild-2011-300591

32 Baqui AH, Ahmed S, Arifeen SE, Darmstadt G, Rosecran A, Mannan I, et al. Effect of timing of first postnatal care home visit on neonatal mortality in Bangladesh: a observational cohort study. BMJ. 2009;339:b2826. Medline:19684100 doi:10.1136/bmj.b2826

33 Mannan I, Rahman SM, Sania A, Seraji HR, Arifeen S, Winch P, et al. Can early postpartum home visits by trained community health workers improve breastfeeding of newborns? J Perinatol. 2008;28:632-40. Medline:18596714 doi:10.1038/ jp. 2008.64

34 Hill Z, Okyere E, Wickenden M, Tawiah-Agyemang C. What can we learn about postnatal care in Ghana if we ask the right questions? A qualitative study. Glob Health Action. 2015;8:28515. Medline:18596714 doi:10.3402/gha.v8.28515

35 Rubayet S, Shahidullah M, Hossain A, Corbett E, Moran A, Mannan I, et al. Newborn Survival in Bangladesh: a Decade of Change and Future Implications. Health Policy Plan. 2012;27:iii40-56. Medline:28156809 doi:10.1093/heapol/czs044

36 Sitrin D, Guenther T, Murray J, Piligram N, Rubayet S, Ligowe R, et al. Reaching mothers and babies with early postnatal home visits: The implementation realities of achieving high coverage in large-scale programs. PLoS One. 2013;8:e68930. Medline:23874816 doi:10.1371/journal.pone.0068930 